\title{
Elastic constants of Ti-15Mo single crystals and their evolution with thermal treatment
}

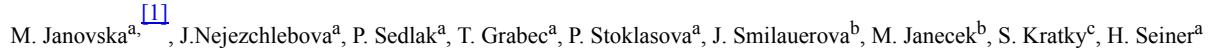 \\ ${ }^{\mathrm{a}}$ Institute of Thermomechanics, Academy of Sciences of the Czech Republic, Dolejškova 5, 18200 Prague, Czech Republic \\ ${ }^{\mathrm{b}}$ Faculty of Mathematics and Physics, Department of Physics of Materials, Charles University, Ke Karlovu 5, 12116 Prague 2, Czech Republic \\ c Institute of Scientific Instruments, Academy of Sciences of the Czech Republic, Královopolská 147,6126 . \\ Republic \\ [1] \\ Corresponding author janovska@it.cas.cz
}

\begin{abstract}
$\underline{\text { Abstract }}$
Elastic constants of single crystals of metastable $\beta$-phase of the Ti-15Mo alloy were studied by ultrasonic methods with the aim to observe the dependence of these constants on formation of isothermal $\omega$ particles. Two ultrasonic methods were applied: resonant ultrasound spectroscopy for monitoring the temperature evolution of the elastic constants, and transient grating spectroscopy for identification of the local material symmetry at a fixed temperature. Samples with different heat treatments (isothermal ageing at $300{ }^{\circ} \mathrm{C}$ and ageing under the same temperature with uniaxial [111] loading) were studied. The results prove that the isothermal omega particles always exactly follow the original cubic symmetry of the $\beta$ matrix, and that the evolutions of the elastic constants of the $\beta-\omega$ multi-phase crystals can be reliably approximated using Hill's homogenizing procedure, assuming cubic elastic constants of the $\beta$ phase and isotropic elastic constants representing the $\omega$ particles.
\end{abstract}

\section{Introduction}

Metastable $\beta$-Ti alloys are used for many of industrial applications because of their variability of strength, toughness and fatigue resistance [1]. Hexagonal $\omega$ particles play an important role in thermomechanical treatment of this alloys because they serve as heterogeneous nucleation sites for precipitation of hexagonal close-packed $\alpha$ particles [2], [3], [4]. The $\omega$ phase has been widely investigated [5], [6]. It is believed that nano-sized particles of athermal $\omega$ phase form by diffusion-less shuffle transformation during quenching from temperatures above $\beta$-transus temperature. Subsequent heating leads to formation of $\omega$ isothermal particles by coupled diffusional-displacive transformation. Alloying elements are rejected from $\omega$ isothermal particles to the surrounding body-centered cubic matrix and a collapse of $\left(\begin{array}{lll}1 & 1 & 1\end{array}\right)_{\beta}$ planes takes place simultaneously during this process [7]. The $\omega$ phase has a significant impact on the elasticity of the whole material, as was shown by Tane [8], so the exact measurement of elasticity can bring new information to explain this problem. Ti15Mo (15 wt. \% of Mo) is a prototypical $\beta$ metastable Ti alloy. Containing only 2 elements, this material is particularly suitable for observing processes which take place during heat treatment of material, such as the $\omega$ particles formation. Ultrasonic methods are very sensitive tools for the measurement of minute changes of the elastic constants of a material and have already been used for the study of metastable $\beta$-Ti alloys [9], [10], [11].

\section{Experimental}

\subsection{Examined material}

Single crystals of Ti15Mo investigated in this study were grown in an optical floating zone furnace. Single crystals of Ti15Mo were grown in an orientation with [111] direction parallel to the length of the single crystal. The single-crystalline ingot was solution treated at $860{ }^{\circ} \mathrm{C}$ for 4 hours in an evacuated quartz tube and subsequently quenched in water [12]. The samples in the form of prisms were cut from solution treated material, and crystallographic orientations of individual faces were checked by Laue method. Subsequently the samples underwent heat treatment under different conditions. The samples after heat treatment were measured by resonant ultrasound spectroscopy (RUS, [13], [14]) at room temperature to obtain full tensor of elastic constants. One of the samples was monitored by RUS during isothermal heating at $300{ }^{\circ} \mathrm{C}$ starting from the solution treated condition. The sample was heated as rapidly as possible to obtain the desired temperature, and hold at this temperature for several hours. Another sample was aged for 4 hours without in-situ RUS monitoring, and the last sample was aged for 6 hours under an unidirectional compression ( $800 \mathrm{MPa}$, applied along the [111] direction). The heat treatment, dimensions and crystallographic orientations of the measured samples are summarized in Table 1. 
Table 1: Dimensions and directional cosines of crystallographic orientation of the measured single crystals

\begin{tabular}{|c|c|c|}
\hline Heat treatment & Dimensions $\left[\mathrm{mm}^{3}\right]$ & Crystallographic orientation \\
\hline $300^{\circ} \mathrm{C} / 4 \mathrm{~h}$ & $4.53 \times 2.5 \times 2.86$ & {$\left[\begin{array}{lll}0.57 & -0.62 & 0.54\end{array}\right] \times\left[\begin{array}{lll}-0.39 & 0.37 & 0.84\end{array}\right] \times\left[\begin{array}{lll}-0.72 & -0.69 & -0.03\end{array}\right]$} \\
\hline $300^{\circ} \mathrm{C} / 800 \mathrm{MPa} / 6 \mathrm{~h}$ & $4.82 \times 3.06 \times 1.72$ & {$\left[\begin{array}{lll}0.31 & -0.52 & -0.79\end{array}\right] \times\left[\begin{array}{lll}-0.79 & -0.61 & 0.09\end{array}\right] \times\left[\begin{array}{lll}0.53 & -0.60 & 0.60\end{array}\right]$} \\
\hline $300^{\circ} \mathrm{C} / 167 \mathrm{~h}$ & $3.86 \times 2.24 \times 1.80$ & {$\left[\begin{array}{llll}0.59 & -0.63 & 0.51\end{array}\right] \times\left[\begin{array}{lll}0.81 & 0.42 & -0.42\end{array}\right] \times\left[\begin{array}{llll}0.06 & 0.65 & 0.75\end{array}\right]$} \\
\hline Accuracy & $\pm 0.01 \mathrm{~mm}$ & $\pm 2^{\circ}$ \\
\hline
\end{tabular}

\subsection{RUS measurement}

The elastic constants of the studied samples were determined by RUS. The fully noncontact set-up described in detail in [15] was used. Prismatic samples with mirror polished upper face were placed in an evacuated chamber with low pressure of nitrogen atmosphere (10 mbar), which enabled a precise temperature control $\left( \pm 0.1^{\circ} \mathrm{C}\right)$ of the examined samples. The vibrations of the sample were excited on its bottom face by infrared laser Nd:YAG laser (Quantel ULTRA, nominal wavelength $1.064 \mu \mathrm{m}$, pulse duration $8 \mathrm{~ns}$ ). Upper face of the sample was scanned by scanning laser vibrometer (Polytec OFV505) to obtain frequencies and modal shapes of individual resonant modes. Resonant spectra of free vibrating samples were recorded in frequency range $0.2-2.5 \mathrm{MHz}$, which covered more than 100 resonant peaks. Between 20 to 50 well detected resonant frequencies from the first 60 resonant modes together with the velocities of longitudinal waves in direction perpendicular to sample faces were involved in inverse procedure to evaluate the full tensor of elastic constant. The cubic symmetry with three independent elastic constants $\left(\mathrm{C}_{11}, \mathrm{C}_{12}\right.$ and $\left.\mathrm{C}_{44}\right)$ was assumed for all measured single crystals. Density of the material was determined from dimensions and weight of individual samples as $\rho=4.93 \mathrm{~g} / \mathrm{cm}^{3}$.

\subsection{TGS measurement}

Transient grating spectroscopy (TGS) is an experimental method for measuring surface acoustic wave (SAW) velocity, involving excitation and detection of narrowband SAWs. In this work, the modification of this setup as described in [16] was used. The narrowband excitation was achieved by sending a pump-beam (1064 nm, pulse energy $90 \mu \mathrm{J}$, pulse duration $400 \mathrm{ps}$ ) through a diffraction transmission grating. The beam was thus divided in two and recombined at the sample surface by a combination of lenses. As a result, the beam was focused onto the free surface of the sample in the form of a periodic array of lines acting as a photoacoustic source of a time-dependent grating. The excited wavelength is determined by the geometry and can be changed by the choice of the diffraction grating. Commonly, the excited wavelengths were in order of tens of micrometers, which corresponds to frequencies in hundreds of MHz. The frequency of the resulting surface vibrations (standing SAWs) was recorded by a continuous wave detection laser beam $(532 \mathrm{~nm}, 200 \mathrm{~mW}$ power) in a heterodyne scheme [17]. The intensity modulations of the probe beam were recorded by two high-speed Si pinphotodiodes in the differential arrangement. Then, the SAW velocity was obtained simply as $v=\lambda f$, with wavelength $\lambda$ given by the excitation geometry, and the frequency $f$ measured. The wavelength of the excited SAWs in our experimental set-up was $10 \mu \mathrm{m}$. The angular dispersion of SAWs was measured by rotation of the sample with respect to the excitation pattern. The velocities were measured in $180^{\circ}$, with the step of $2^{\circ}$. Then, the elastic constants of the sample were obtained from an inverse procedure, with initial values taken from the RUS measurement. To stabilize the calculation, the longitudinal wave velocities measured by pulse-echo method on all three sides of the sample were considered [15]

\section{Experimental results and discussion}

Three solution treated single crystalline samples were subjected to isothermal heat treatment at $300{ }^{\circ} \mathrm{C}$. One of the samples was in situ measured by RUS to observe $\omega$ particles formation during isothermal ageing, the cooling run from the ageing temperature to room temperature was monitored too. The sample was in total aged for 167 hours. Evolutions of shear elastic constants $\mathrm{C}_{44}$ and $\mathrm{C}^{\prime}$ were determined from measured resonant spectra and are shown in figure $1 \mathrm{a}$ ) and c). Insets display the same dependences on time in logarithmic scale. Significant increase is observed for both shear elastic constants after the period of heat treatment, $16 \%$ for $\mathrm{C}_{44}$ and $28 \%$ for $\mathrm{C}^{\prime}$. The highest increase of both elastic constants is observed at the beginning of the ageing and 
subsequently slows down. Evolution of both elastic constants during cooling runs from $300{ }^{\circ} \mathrm{C}$ to room temperature are shown in figure $1 \mathrm{~b}$ ) and $1 \mathrm{~d}$ ). Room temperature cubic elastic constants after heat treatment of examined single crystals $\mathrm{C}_{11}, \mathrm{C}_{12}, \mathrm{C}_{44}$ together with constant $\mathrm{C}^{\prime}=\left(\mathrm{C}_{11}-\mathrm{C}_{12}\right) / 2$ representing the softest shear in unstable or metastable cubic lattice, and anisotropy factor ratio between the shear moduli $\mathrm{C}_{44}$ and $\mathrm{C}^{\prime}$ are summarized in Table 2.

Table 2: Room temperature cubic elastic constants Ti15Mo samples after heat treatment determined by RUS

\begin{tabular}{|l|l|l|l|l|l|}
\hline \multicolumn{1}{|c|}{ sample } & $\mathrm{C}_{11}[\mathrm{GPa}]$ & $\mathrm{C}_{12}[\mathrm{GPa}]$ & $\mathrm{C}_{44}[\mathrm{GPa}]$ & $\mathrm{C}^{\prime}[\mathrm{GPa}]$ & $\mathrm{A}=\mathrm{C}_{44} / \mathrm{C}^{\prime}$ \\
\hline $300^{\circ} \mathrm{C} / 4 \mathrm{~h}$ & $153.7 \pm 1$ & $86.4 \pm 0.6$ & $54.6 \pm 0.5$ & $33.6 \pm 0.5$ & $1.63 \pm 0.05$ \\
\hline $300^{\circ} \mathrm{C} / 800 \mathrm{MPa} / 6 \mathrm{~h}$ & $159 \pm 0.8$ & $87.8 \pm 0.6$ & $55.3 \pm 0.3$ & $35.6 \pm 0.3$ & $1.55 \pm 0.04$ \\
\hline $300^{\circ} \mathrm{C} / 167 \mathrm{~h}$ & $160.8 \pm 0.8$ & $85.6 \pm 0.6$ & $55.9 \pm 0.3$ & $37.6 \pm 0.3$ & $1.49 \pm 0.04$ \\
\hline
\end{tabular}

Two samples, one aged for $4 \mathrm{~h}$ at $300{ }^{\circ} \mathrm{C}$ and one aged for $6 \mathrm{~h}$ at the same temperature $\left(300{ }^{\circ} \mathrm{C}\right)$ under uniaxial loading in $\left[\begin{array}{lll}1 & 1 & 1\end{array}\right]$ direction, were measured at room temperature by TGS method to observe local material symmetry of the samples. The measurements were done on the faces of the samples cut approximately along the (lll $\left.1 \begin{array}{ll}1 & 0\end{array}\right)$ planes. Room temperature elastic constants computed from measured velocities are shown in Table 3. Measured velocities of SAWs in this plane are displayed in Figure 2 together with velocities computed from elastic constants determined by RUS and TGS methods. The sample that underwent ageing at $300{ }^{\circ} \mathrm{C}$ without additional loading is displayed in fig. 2a). It is clearly seen that measured velocities agree very well with velocities computed from cubic elastic constants determined by RUS and with velocities determined by TGS method too. Results for the sample heated under uniaxial loading in $\left[\begin{array}{lll}1 & 1 & 1\end{array}\right]$ direction are displayed in fig. 2b). In this case, the agreement between measured velocities and velocities computed from elastic constants determined by TGS method is again very good, however velocities computed from elastic constants determined by RUS are not in such a good agreement with measured velocities as in previous case, which may indicate slight breaking of the perfect cubic symmetry due to prestress. Nevertheless, this material is still very well described by cubic symmetry. Also the agreement between the elastic constants from RUS and TGS measurements is satisfactory.

Table 3: Room temperature cubic elastic constants Ti15Mo samples after heat treatment determined by TGS

\begin{tabular}{|l|l|l|l|l|l|}
\hline sample & $\mathrm{C}_{11}[\mathrm{GPa}]$ & $\mathrm{C}_{12}[\mathrm{GPa}]$ & $\mathrm{C}_{44}[\mathrm{GPa}]$ & $\mathrm{C}^{\prime}[\mathrm{GPa}]$ & $\mathrm{A}=\mathrm{C}_{44} / \mathrm{C}^{\prime}$ \\
\hline $300^{\circ} \mathrm{C} / 4 \mathrm{~h}$ & $154.9 \pm 1$ & $87.3 \pm 0.5$ & $54.6 \pm 0.4$ & $33.8 \pm 0.4$ & $1.62 \pm 0.05$ \\
\hline $300^{\circ} \mathrm{C} / 800 \mathrm{MPa} / 6 \mathrm{~h}$ & $160.2 \pm 0.8$ & $90.4 \pm 0.6$ & $54.9 \pm 0.4$ & $34.9 \pm 0.4$ & $1.57 \pm 0.04$ \\
\hline
\end{tabular}

If the studied material is considered as a mixture of cubic $\beta$ matrix and isotropic $\omega$ particles, the obtained sets of elastic constants enable estimation of volume fractions of isothermal $\omega$ particles in the examined samples. Using the Hill's averaging scheme described in [12] and the effective room temperature elastic constants of isothermal $\omega$ particles from [12], the RUS results give approximately $52 \%$ and $54 \%$ volume fractions for the $300{ }^{\circ} \mathrm{C} / 4 \mathrm{~h}$ and $300^{\circ} \mathrm{C} / 800 \mathrm{MPa} / 6 \mathrm{~h}$ samples, respectively, and $57 \%$ for the $300^{\circ} \mathrm{C} / 167 \mathrm{~h}$ sample. The method of $\omega$ volume fraction estimation from shear elastic constants is in detail described in our previous work [12]. The samples used for purpose of the study were checked by TEM to prove that only $\beta$ and $\omega$ phases are present. As samples used in this study were heat treated under similar condition, this assumption is relevant also in this case. 

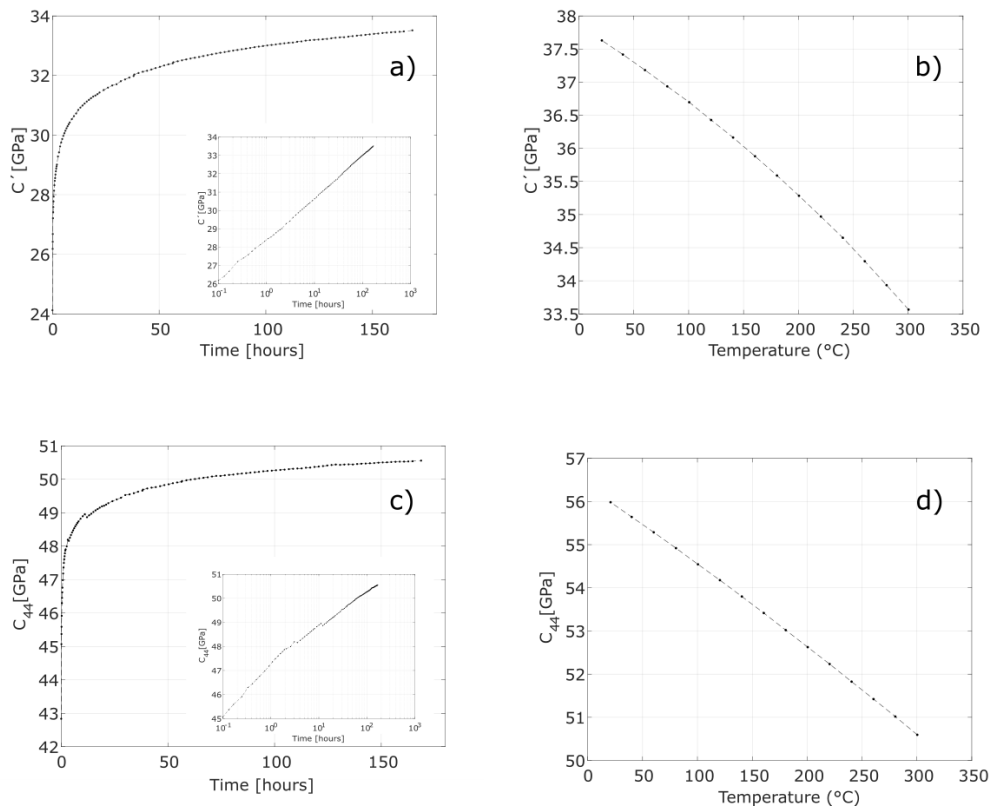

Figure 1: Evolution of shear elastic constants a) $C^{\prime}$ and c) $C_{44}$ during isothermal ageing and during cooling run b) and c) respectively
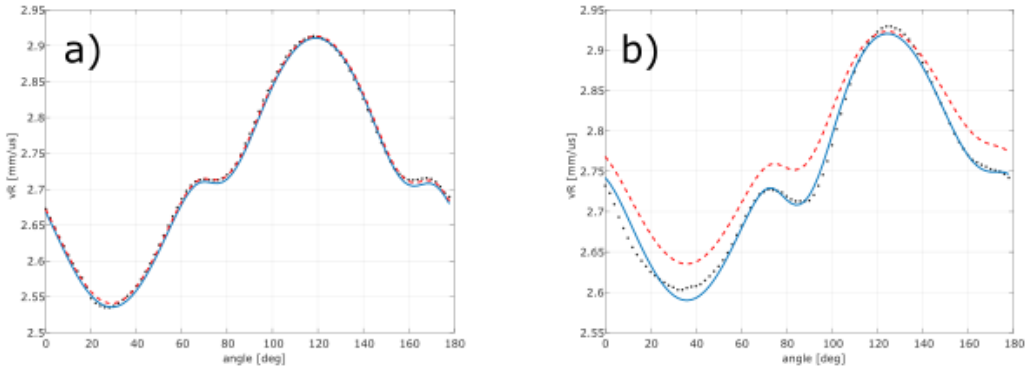

Figure 2: SAW velocities a) in a (-0.72 -0.69-0.03) plane of the Ti15Mo sample aged at $300{ }^{\circ} \mathrm{C}$ for 4 hours b) in a ( $\left.-0.15-0.110 .02\right)$ plane of Ti15Mo single crystal aged at $300{ }^{\circ} \mathrm{C}$ under uniaxial loading in $\left[\begin{array}{lll}1 & 1 & 1\end{array}\right]$ direction for 6 hours. (Black ... measured data, Red - - - SAW velocities for elastic constants determined by RUS, Blue — SAW velocities for elastic constants determined by TGS). [ [ 111 1] direction corresponds to 0 deg.

\section{Conclusions}

The effect of microstructure evolution on elastic constants of Ti15Mo was studied by ultrasonic methods. A significant increase of shear elastic constants $\mathrm{C}$ ' and $\mathrm{C}_{44}$ was observed as a result of isothermal ageing of single crystalline samples at $300{ }^{\circ} \mathrm{C}$. The increase of shear elastic constants originates from the formation of $\omega$ isothermal particles during isothermal ageing and their growth due to exclusion of $\beta$ stabilizing element Mo to $\beta$ matrix. RUS and TGS results proved that the cubic symmetry of the crystals remains approximately preserved also after isothermal ageing under uniaxial compressive loading in $\left[\begin{array}{lll}1 & 1 & 1\end{array}\right]$ direction. This symmetry preservation appears not just globally (the RUS measurements) but also locally, as indicated by the TGS measurement in a small spot at one of free surfaces of the sample. 


\section{Acknowledgement}

This work was supported by the project of the Czech Science Foundation (17-04871S) and by the project of Industry and Trade (FV10618).

\section{References}

[1] D. Banerjee, J.C. Williams, Perspectives on Titanium Science and Technology, Acta Mater. 61 (2013) 844-879. doi:10.1016/J.ACTAMAT.2012.10.043.

[2] F. Prima, P. Vermaut, G. Texier, D. Ansel, T. Gloriant, Evidence of $\alpha$ nanophase heterogeneous nucleation from $\omega$ particles in a $\beta$-metastable Ti based alloy by high-resolution electron microscopy, Scr. Mater. 54 (2006) 645-648. doi:10.1016/j.scriptamat.2005.10.024.

[3] S. Nag, R. Banerjee, R. Srinivasan, J.Y. Hwang, M. Harper, H.L. Fraser, $\omega$-Assisted nucleation and growth of $\alpha$ precipitates in the Ti5A15Mo5V3Cr0.5Fe $\beta$ titanium alloy, Acta Mater. 57 (2009) 2136-2147. doi:10.1016/j.actamat.2009.01.007.

[4] J. Smilauerova, M. Janecek, P. Harcuba, J. Strasky, J. Vesely, R. Kuzel, H.J. Rack, Ageing response of sub-transus heat treated Ti6.8Mo4.5Fe1.5Al alloy, J. Alloys Compd. 724 (2017) 373-380. doi:10.1016/J.JALLCOM.2017.07.036.

[5] D. De Fontaine, N. Paton, J. Williams, The omega phase transformation in titanium alloys as an example of displacement controlled reactions, Acta Metall. 19 (1971) 1153-1162. doi:10.1016/0001-6160(71)90047-2.

[6] H.P. Ng, A. Devaraj, S. Nag, C.J. Bettles, M. Gibson, H.L. Fraser, B.C. Muddle, R. Banerjee, Phase separation and formation of omega phase in the beta matrix of a TiVCu alloy, Acta Mater. 59 (2011) 2981-2991. doi:10.1016/J.ACTAMAT.2011.01.038.

[7] A. Devaraj, S. Nag, R. Srinivasan, R.E.A. Williams, S. Banerjee, R. Banerjee, H.L. Fraser, Experimental evidence of concurrent compositional and structural instabilities leading to $\omega$ precipitation in titaniummolybdenum alloys, Acta Mater. 60 (2012) 596-609. doi:10.1016/j.actamat.2011.10.008.

[8] M. Tane, Y. Okuda, Y. Todaka, H. Ogi, A. Nagakubo, Elastic properties of single-crystalline $\omega$ phase in titanium, Acta Mater. 61 (2013) $7543-7554$. doi:10.1016/J.ACTAMAT.2013.08.036.

[9] J. Nejezchlebova, H. Seiner, P. Sedlak, M. Landa, J. Smilauerova, E. AebyGautier, B. Denand, M. Dehmas, B. Appolaire, On the complementarity between resistivity measurement and ultrasonic measurement for in-situ characterization of phase transitions in Ti-alloys, J. Alloys Compd. 762 (2018) 868-872. doi:10.1016/J.JALLCOM.2018.05.173.

[10] J. Nejezchlebova, M. Janovska, H. Seiner, P. Sedlak, M. Landa, J. Smilauerova, J. Strasky, P. Harcuba, M. Janecek, The effect of athermal and isothermal $\omega$ phase particles on elasticityof $\beta$-Ti singlecrystals, ActaMater. 110 (2016) 185-191. doi:10.1016/J.ACTAMAT.2016.03.033.

[11] K. Vaclavova, J. Strasky, V. Polyakova, J. Straska, J. Nejezchlebova, H. Seiner, I. Semenova, M. Janecek, Microhardness and microstructure evolution of ultra-fine grained Ti-15Mo and TIMETAL LCB alloys prepared by high pressure torsion, Mater. Sci. Eng. A. 682 (2017) 220-228.

doi:10.1016/j.msea.2016.11.038.

[12] J. Nejezchlebová, M. Janovská, P. Sedlák, J. Šmilauerová, J. Stráský, M. Janeček, H. Seiner, Elastic constants of $\beta$-Ti15Mo, J. Alloys Compd. 792, (2019), 960-967. doi:/10.1016/j.jallcom.2019.03.418

[13] R.G. Leisure, F.A. Willis, Resonant ultrasound spectroscopy, J. Phys. Condens. Matter. 9 (1997) 6001-6029. doi:10.1088/0953-8984/9/28/002.

[14] A. Migliori, T.W. Darling, Resonant ultrasound spectroscopy for materials studies and non-destructive testing, Ultrasonics. 34 (1996) $473-476$. doi:10.1016/0041-624X(95)00120-R.

[15] P. Sedlak, H. Seiner, J. Zidek, M. Janovska, M. Landa, Determination of All 21 Independent Elastic Coefficients of Generally Anisotropic Solids by Resonant Ultrasound Spectroscopy: Benchmark Examples, Exp. Mech. 54 (2014) 1073-1085. doi:10.1007/s11340-014-9862-6.

[16] Grabec, T., P. Sedlak, P. Stoklasova, M. Thomasova, D. Shilo, et al.In-situ Characterization of Local Elastic Properties of Thin Shape Memory Films by Surface Acoustic Waves. Smart Mater. Struct., 2016. vol. 25(12). doi:10.1088/0964-1726/25/12/127002.

[17] Maznev, A. A., K. A. Nelson, and J. A. Rogers. Optical heterodyne detectionof laser-induced gratings. Opt. Lett., 1998. vol. $23(16), 1319\{1321$. doi:10.1364/OL.23.001319. 